\title{
Ensino de BIM em curso de graduação em engenharia civil em uma universidade dos EUA: estudo de caso
}

\author{
Teaching of BIM in undergraduate program in civil \\ engineering of an american university: case study
}

\section{Priscilla Elisa de Azevedo Basto Alberto Casado Lordsleem Junior}

\section{Resumo}

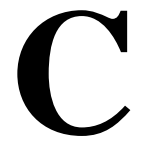

om o crescente avanço da tecnologia, os empreendimentos da construção civil se tornam cada vez mais complexos. Como forma de acompanhar esse processo, foi desenvolvido o paradigma denominado de Building Information Modeling (BIM), que se baseia na colaboração entre as equipes para a elaboração de um modelo integrado e 3D da edificação do qual serão retiradas as informações necessárias para a gestão do empreendimento. O BIM vem sendo utilizado por diversas empresas, devido aos benefícios potenciais, entretanto sua difusão continua sendo restrita em razão do fato de ser dominado por pequena quantidade de profissionais. Dessa forma, este trabalho objetiva descrever um método de abordagem do ensino de BIM, permitindo a sua avaliação para potencial difusão e utilização, e demonstrar a importância desse método. Para isso foram realizadas a descrição detalhada e a análise da experiência de ensino do BIM na disciplina de Gerenciamento de Projeto da Construção I, ministrada na Arizona State University (ASU), localizada nos Estados Unidos. Através dos resultados obtidos, constatou-se que a disciplina realiza a abordagem do BIM em conjunto com os outros assuntos, pode ser classificada como de nível intermediário, formando um analista BIM, e se mostrou efetiva em apresentar os principais conceitos e usos do BIM aos discentes.

Palavras-chaves: Building Information Modeling. Ensino de BIM. Engenharia civil. Arizona State University.

Priscilla Elisa de Azevedo Basto Universidade de Pernambuco Olinda - PE -Brasil

Alberto Casado Lordsleem Júnior Universidade de Pernambuco Recife - PE - Brasil

Recebido em 15/04/16 Aceito em 04/07/16

\begin{abstract}
With the increasing advance of technology the construction of buildings become more complex. In order to follow this process, it was developed the paradigm named Building Information Modeling (BIM). It is based on collaboration between the architectural, engineering and construction professionals for the development of an integrated $3 D$ model of a building from which necessary information will be set aside for the project management. BIM has been used by many companies, due to potential benefits. However, the diffusion of this paradigm remains limited by the small number of professionals who dominate it. Thus, this study aims to demonstrate the importance of BIM and describe a method of teaching it, so this paradigm could be widespread and used by many students. For this purpose, it was made an analysis of BIM teaching-learning experience in the class of Construction project management I, taught at Arizona State University (ASU), located in United States. From the results it was found that this class introduce concepts of BIM with others project management subjects, it may be classified as intermediate level, forming a BIM analyst, and it is effective in present some of mainly concepts and uses of BIM to the class.

Keywords: Building Information Modeling. BIM education. Civil engineering. Arizona State University.
\end{abstract}




\section{Introdução}

Cada vez mais a indústria da Arquitetura, Engenharia e Construção (AEC) reconhece a importância de uma integração entre os profissionais responsáveis pelo processo de planejamento e execução de um empreendimento. Para alcançar esse objetivo, algumas empresas estão desenvolvendo projetos de arquitetura e engenharia utilizando a Modelagem da Informação da Construção, do inglês Building Information Modeling (BIM).

Segundo Godoy, Cardoso e Borges (2013), o BIM constitui-se numa mudança de paradigma entre apresentar a informação sobre a construção a ser executada e representar essa informação. Esse paradigma permite que todas as informações de um empreendimento, desde a fase de concepção até a de desconstrução, sejam representadas por meio de um modelo digital criado pelo conjunto de dados agregados referentes às especialidades de cada profissional envolvido no ciclo de vida da edificação (SANTOS; BARISON, 2011). Desse modo, o BIM pode contribuir para solucionar a fragmentação das informações, que resulta em problemas como falta de compatibilidade entre os projetos de arquitetura e engenharia, perda de documentos e baixa produtividade.

O desenvolvimento de um plano de execução detalhado sobre a implementação do BIM no projeto é importante para a efetiva integração desse paradigma. Assim, o Building Information Modeling Project Execution Planning (PxP) cria uma visão geral com alguns detalhes da implementação que devem ser seguidos pelas partes envolvidas no projeto (COMPUTER..., 2011). Como forma de auxiliar os profissionais no desenvolvimento do PxP foi criado pelo The Computer Integrated Construction Research Program da Pennsylvania State University o Guia do Plano de Execução do Projeto de BIM. Esse guia estabelece um procedimento que inclui quatro etapas, apresentados na Figura 1.

Assim, para atender a demanda crescente de empresas na utilização da tecnologia BIM, é desejável a efetiva inclusão de seus conceitos nos currículos de graduação de AEC, a fim de permitir a preparação dos futuros profissionais da indústria. No entanto, a incorporação das competências e dos conhecimentos necessários está ocorrendo de maneira lenta, sendo clara a essencialidade de incentivo às universidades para a adoção de BIM durante o ensino da graduação (CLEVENGER et al., 2010; BARISON; SANTOS, 2010).
Este trabalho realiza a descrição e a análise de um estudo de caso sobre o ensino de Modelagem da Informação da Construção na disciplina de Gerenciamento do Projeto da Construção I, do inglês Construction Project Management I (CPM I) na universidade norte-americana Arizona State University (ASU).

\section{Modelagem da Informação da Construção (BIM)}

É fato que os desenhos e modelos geométricos em CAD, em muitos casos, não estão mais sendo suficientes para a representação e o gerenciamento dos projetos de empreendimentos que se tornam cada vez mais complexos. Isso se deve porque os documentos são desenvolvidos de forma independente e são apresentados separadamente, em grande parte por profissionais projetistas de especialidades distintas em escritórios que não compartilham as informações de seus projetos durante o desenvolvimento. Além disso, esses documentos excluem uma série de informações como orçamentos, cronogramas, especificações de materiais, entre outros (INFOCOMM..., 2011).

Dentro do conceito geral podem ser dadas várias interpretações para a sigla BIM, os significados mais utilizados são: Building Information Model (Modelo da Informação da Construção), que é uma representação digital baseada na modelagem orientada a objetos, inteligentes e paramétricos das características físicas e funcionais de um edifício; Building Information Modeling (Modelagem da Informação da Construção), que é o processo de utilização de plataformas tecnológicas interoperáveis para gerar e utilizar dados de forma eficiente para o planejamento, a construção e a operação de uma edificação durante todo o seu ciclo de vida, modificando as funções e relações entre os profissionais, através do estimulo à colaboração de todas as partes envolvidas e o acesso simultâneo às informações criadas por elas (ASSOCIATED..., 2006; NATIONAL..., 2015); e Building Information Management (Gerenciamento de Informação da Construção), que trata da organização e do controle do processo de gerenciamento por meio da utilização das informações contidas no modelo digital para efetuar o compartilhamento de informações durante todo o ciclo de vida do empreendimento (NATIONAL..., 2015).

46 Basto, P. E. de A.; Lordsleem Junior, A. C. 
Figura 1 - Procedimento para desenvolvimento do Plano de Execução do Projeto BIM

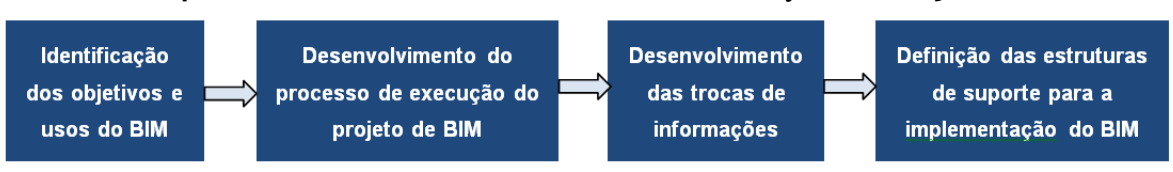

Fonte: modificado de CICRG (COMPUTER..., 2011).

O modelo paramétrico possui objetos com atribuições e representações próprias, associados a dados e regras. Ele não se trata apenas de um desenho, mas sim de uma geometria integrada, em que qualquer alteração feita em uma das vistas será modificada em todas as demais, e é automaticamente alterado quando há qualquer mudança em elementos associados ao objeto (EASTMAN et al., 2011; COSTA, 2013 ${ }^{1}$ apud MELO, 2014; CHECCUCI, 2014).

A modelagem da informação pode ser utilizada durante todo o ciclo de vida da edificação, aproximando os profissionais desde os primeiros estágios de planejamento do empreendimento. De acordo com Mello (2012), em cada uma das etapas o modelo vai adquirindo informações e crescendo em conjunto com o empreendimento.

A Figura 2 apresenta exemplos de atividades em que o BIM pode estar inserido dentro das etapas do ciclo de vida do empreendimento. Em amarelo se encontra a fase de projeto, na qual são realizados o planejamento, mais voltado ao produto, a modelagem inicial, as análises e as simulações, e é gerada a documentação necessária das demais etapas. Em seguida, em laranja, encontra-se a fase da construção, na qual são gerados as simulações das etapas da execução (modelo 4D) e os custos atrelados às diversas atividades da obra (modelo 5D), além dos desenhos utilizados para os elementos pré-fabricados e os projetos de disposição do canteiro de obra em diferentes períodos. Por fim, em vermelho, apresentam-se as fases de operação, manutenção, renovação ou desconstrução do empreendimento.

É importante salientar que para o processo culminar em um modelo confiável e com dados fiéis àqueles que serão encontrados no fim da obra é preciso que a qualidade do modelo seja garantida em cada etapa.

Segundo o PMI (PROJECT..., 2008), um projeto é um esforço empreendido temporariamente com o objetivo de criar um produto, serviço ou resultado exclusivo, que em geral serão duradouros. Assim, o projeto possui início e término determinados e,

${ }^{1}$ COSTA, E. N. Avaliação da Metodologia BIM Para a Compatibilização de Projetos. Ouro Preto, 2013. $84 \mathrm{f}$ Dissertação (Mestrado em Engenharia Civil) - Escola de Engenharia, Universidade Federal de Ouro Preto, Ouro Preto, 2013. apesar de possuir similaridades com outros produtos de uma mesma área, é único.

Além disso, o projeto deve possuir um objetivo, que justifique sua criação e modo de desenvolvimento. É composto de atividades interdependentes e é realizado em conjunto com outros projetos, por isso é essencial a integração entre as diferentes partes (DINSMORE; CABANIS-BREWIN, 2009; SILVA; CIM, 2012).

Neste trabalho a palavra projeto (do inglês project) possui uma definição voltada ao resultado, ou seja, o empreendimento em si. Este abrange informações tecnológicas e gerenciais dos projetos de arquitetura, estruturas, instalações hidráulicas, instalações elétricas, instalações mecânicas, e demais projetos complementares, com seus elementos, instalações e componentes construtivos, desde seu planejamento até o fim do seu ciclo de vida. Por isso, o gerenciamento de projeto é necessário para administrar as múltiplas áreas envolvidas no projeto, a fim de atender, no fim da obra, os objetivos inicialmente estabelecidos.

No PMBOK (PROJECT..., 2008, p. 11) gerenciamento de projeto é descrito como "[...] a aplicação de conhecimento, habilidades, ferramentas e técnicas às atividades de um projeto [...]", garantindo que seu propósito seja alcançado. No sentido de gerenciamento do empreendimento, Melhado et al. (2008) afirmam que a coordenação de projetos é uma atividade que auxilia o desenvolvimento do projeto e que tem o objetivo de incentivar a interatividade entre os profissionais envolvidos, melhorando a sua qualidade. Portanto, o gerente de projeto é aquele que é responsável por garantir que as soluções técnicas apresentadas pelas equipes especializadas alcancem os objetivos almejados pelo cliente.

No gráfico apresentado na Figura 3 constata-se que, em geral, as alterações realizadas durante o planejamento do projeto impactam em menor escala o custo e o pessoal quando comparado com aquelas alterações realizadas durante sua execução, que exigiriam decisões rápidas e que poderiam afetar o cronograma da obra. Por meio do compartilhamento e da contribuição de todas as partes envolvidas desde o início do projeto, as alterações durante as fases de execução ou encerramento do projeto podem ser minimizadas. 
Figura 2 - BIM no ciclo do empreendimento

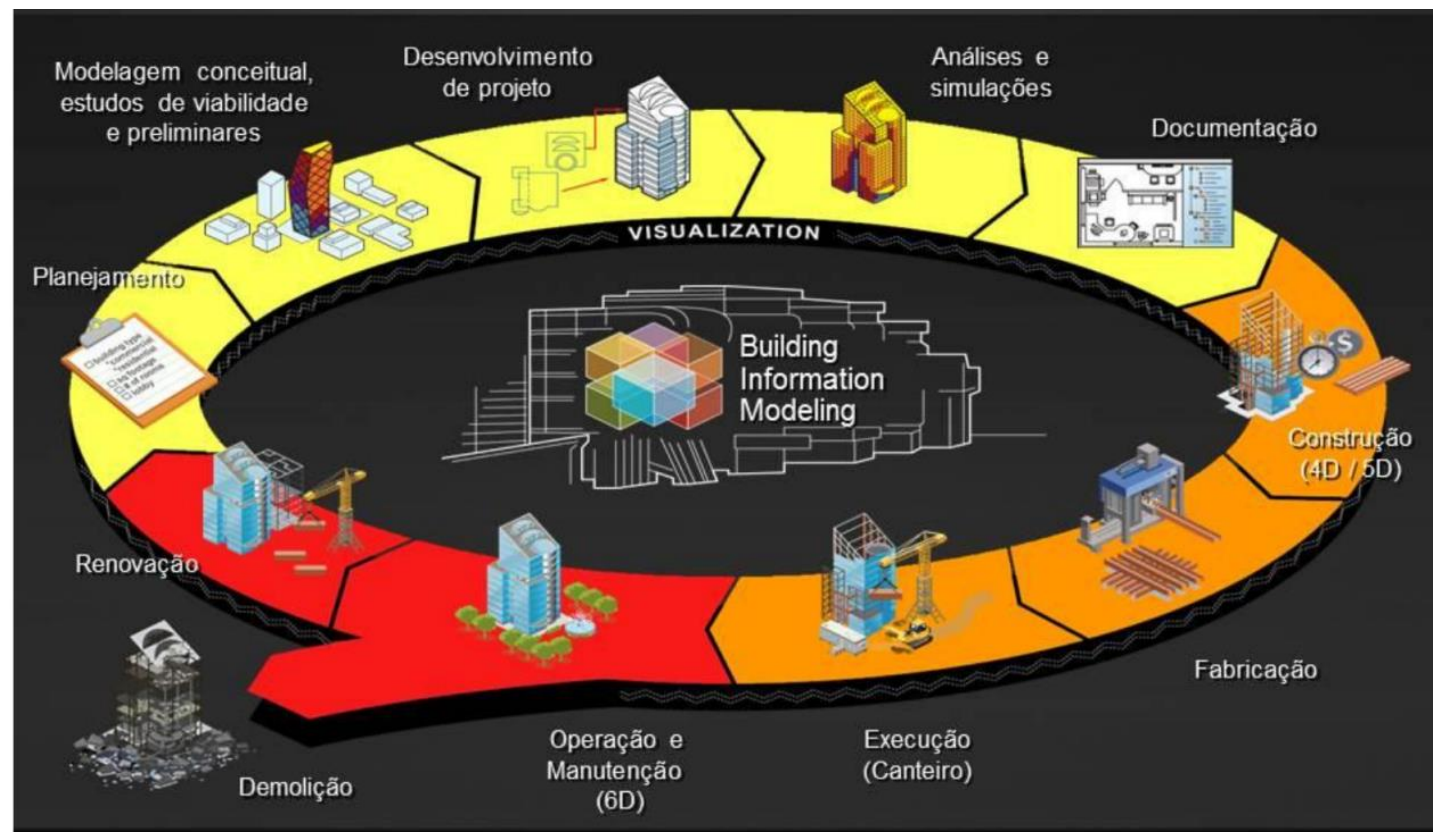

Fonte: Mello (2012).

Figura 3 - Nível típico de custos e pessoal ao longo do ciclo de vida do empreendimento

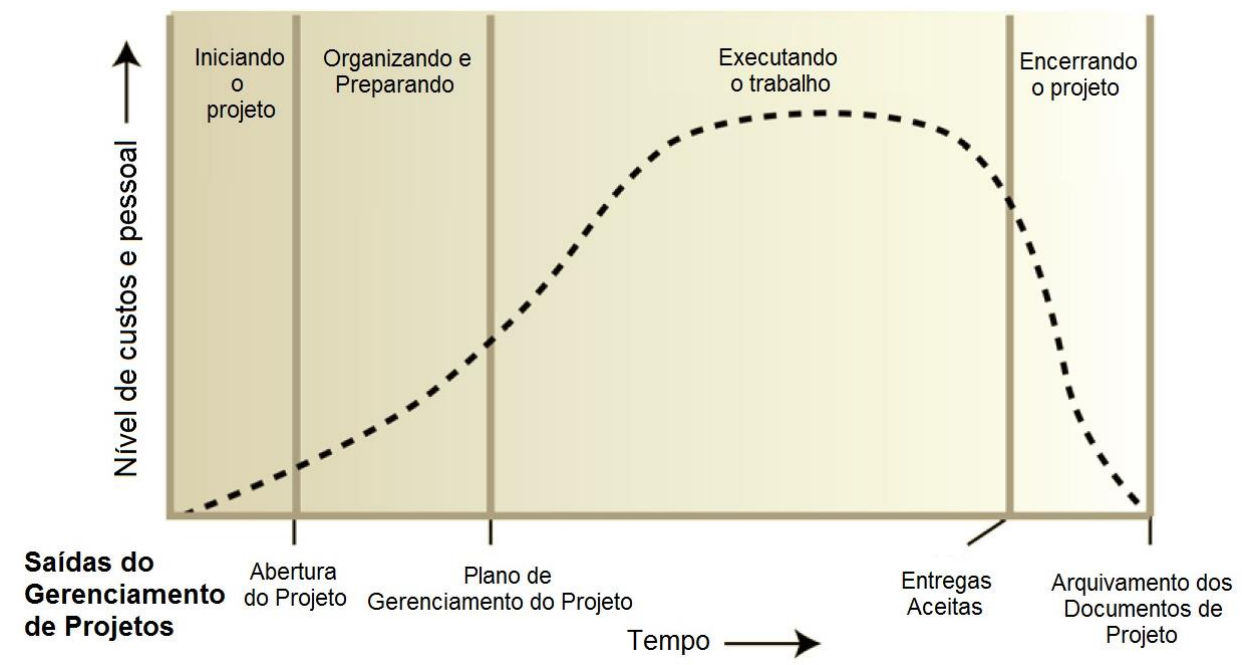

Fonte: modificado de PMI (PROJECT..., 2008).

Portanto, a Modelagem da Informação da Construção pode contribuir para que seja realizado um planejamento cuidadoso desde os primeiros estágios do projeto do empreendimento, através do incentivo à colaboração dos profissionais e da simulação e compatibilização dos elementos, instalações e componentes construtivos da edificação.

Além de auxiliar no gerenciamento do projeto, pode-se destacar como vantagens do BIM: visualização de um modelo digital em 3D; modelos para fabricação de elementos pré- fabricados; revisão de projetos; estimativa de custo; esquematização da sequência de construção; análise de possíveis falhas de projeto; detecção de conflitos, interferências e colisões entre os diferentes sistemas do projeto; compartilhamento de informações; e simulações de desempenho acústico e de iluminação e do comportamento estrutural (AZHAR, 2011; INFOCOMM..., 2011; CHECCUCCI, 2014).

Durante a execução da edificação, o BIM pode proporcionar a visualização das etapas de construção em razão do tempo, as diferentes

48 Basto, P. E. de A.; Lordsleem Junior, A. C. 
disposições do canteiro de obras para cada fase, e a possibilidade de acesso ao projeto por dispositivos móveis para uso em campo.

Assim, os benefícios da Modelagem da Informação da Construção contemplam desde o dono do empreendimento até os arquitetos, os projetistas, os engenheiros, o gerente da edificação e outros trabalhadores do canteiro, fazendo com que o projeto do empreendimento se desenvolva de forma mais eficiente e sejam otimizados os controles de qualidade, já que o modelo permite que as diversas partes envolvidas tenham acesso aos dados e se comuniquem entre si, o que permite que erros sejam identificados de forma mais fácil (INFOCOMM..., 2011).

Algumas das principais desvantagens do BIM estão associadas à mudança cultural e aos custos dos investimentos na aquisição, manutenção e aprimoramento das licenças de software, que representam um gasto maior do que aqueles desenvolvidos com programas CAD disponíveis. É importante destacar também que os custos envolvidos na formação de pessoal e na construção de bibliotecas para a construção dos modelos são expressivos na fase de implantação do BIM. No entanto, entende-se que com o passar dos anos o custo de capacitação decresce e o custo com a constante necessidade de atualização tecnológica acaba por ser mais significativo. Esses investimentos também se estendem ao aumento de desempenho do hardware, que deve possuir os requisitos necessários para atender os parâmetros de modelagem da informação e manter o desempenho durante a utilização (INFOCOMM..., 2011).

Souza, Amorim e Lyrio (2009) e Checcucci (2014) defendem que o treinamento e a transmissão de conhecimento dos funcionários devem ser considerados como parte integrante dos custos, e alertam como desvantagem o declínio na curva de produtividade durante as fases iniciais de aprendizagem.

Outra mudança que pode causar desafios inicialmente é a forma como são estabelecidas as relações entre os profissionais de AEC. Estes devem trabalhar de forma colaborativa e integrada, e não desempenhar suas funções independentemente. Para isso devem ser definidas estratégias de compartilhamento de informações e reuniões para discussão do andamento do trabalho (AZHAR, 2011; EASTMAN et al., 2011).

Desse modo, a ausência de um agente que impulsione um primeiro contato com esse paradigma faz com que seu uso ainda seja limitado. Por isso, é preciso que seus conceitos sejam cada vez mais difundidos, evitando que o pouco conhecimento sobre o tema se torne uma barreira para sua implantação.

\section{Ensino de BIM nas universidades}

Com o crescente interesse da indústria de AEC pela utilização da Modelagem da Informação da Construção, a procura por profissionais com conhecimento e domínio sobre o paradigma também se torna cada vez maior. No entanto, a falta de pessoal capacitado ou que conheça os benefícios que a mudança de metodologia traria acaba por criar dificuldades na aplicação do BIM (LINO; AZENHA; LOURENÇO, 2012; GODOY; CARDOSO; BORGES, 2013).

Segundo Sabongi (2009), Sacks e Pikas (2013) e Checcucci (2014), a introdução de BIM nas universidades ocorre de maneira lenta devido a alguns desafios, como: novos métodos de ensino; deficiência de materiais, livros e outras fontes específicas; dificuldade de encontrar docentes preparados; custo das plataformas; multidisciplinaridade requerida; criação de componentes curriculares; e carência de normas/requisitos para a implementação no currículo.

Apesar dos obstáculos citados, algumas universidades obtiveram sucesso na implantação do BIM na grade curricular. Segundo Barison e Santos (2011), nos Estados Unidos, a Georgia Institute of Technology foi precursora do movimento da introdução das ferramentas BIM ao realizar pesquisas desde a década de 1990, tendo sido seguida pela maioria das demais universidades americanas a partir de 2003. Além desse, os autores reuniram os principais acontecimentos relacionados ao ensino de BIM nos EUA em uma linha do tempo apresentada na Figura 4.

No âmbito nacional, de acordo com Ruschel, Andrade e Morais (2013), a difusão das discussões sobre BIM foi impulsionada pela crescente preocupação com a implementação da Modelagem de Informação da Construção nos cursos de Arquitetura e Engenharia Civil. Algumas universidades brasileiras, citadas pelos autores, que já estão trabalhando conteúdos referentes ao BIM em seus currículos com sucesso, são a Universidade Federal de Alagoas (AL), o Centro Universitário Barão de Mauá (SP), a Universidade Presbiteriana Mackenzie (SP), a Universidade Federal de São Carlos (SP) e a Universidade Estadual de Campinas (SP). 
Figura 4 - Evolução do ensino de BIM nos EUA

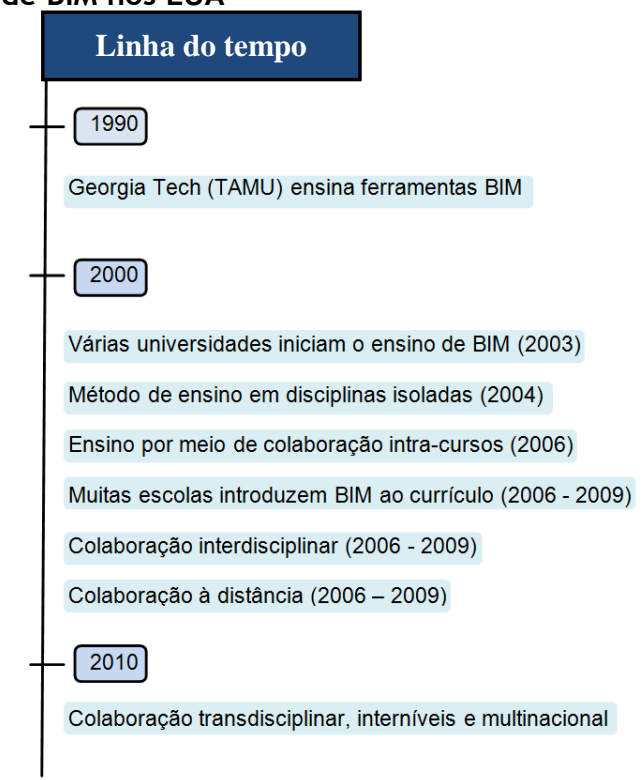

Fonte: modificado de Barison e Santos (2010).

Em seu artigo, Pereira e Ribeiro (2014) fazem uma investigação a respeito da capacitação no uso de BIM, de modo a conhecer pesquisas que abordam essa questão e as possibilidades de inserção integrada nas disciplinas de graduação de Engenharia Civil no Brasil. Para isso os autores desenvolveram um questionário que foi respondido por 48 professores de universidades brasileiras públicas e privadas. Em seus resultados constataram que mais da metade desses docentes (62\%) possui mais de 15 anos de docência, e se encontram na área de atuação de construção civil $(35 \%)$ e estruturas $(25 \%)$. No entanto, dentre esses profissionais apenas $27 \%$ já utilizaram BIM durante sua atividade de docência, em que a maioria (58\%) trata do assunto de forma introdutória, ou seja, o enfoque fica na modelagem paramétrica (PEREIRA; RIBEIRO, 2014).

Passando aos métodos de ensino de BIM, Barison e Santos (2011) relatam que atualmente a estratégia de inserção da Modelagem da Informação da Construção no currículo pode ser dividida em duas abordagens: a criação de novas disciplinas com o conteúdo específico de BIM ou sua introdução em diversas disciplinas existentes como recurso de auxílio ao entendimento (BARISON; SANTOS, 2011). Os autores seguem afirmando que podem ser encontradas algumas abordagens semelhantes nas universidades que introduziram o BIM em sua grade curricular, entre elas estão: a representação gráfica digital, o workshop, o ateliê de projeto, a disciplina específica de BIM, a tecnologia da construção, o gerenciamento da construção, o trabalho de conclusão de curso e o estágio curricular.
Para Kymmell (2008), o conteúdo abordado nas universidades deve ser o mesmo demandado dos profissionais de AEC, porém o estudante necessitará de um contexto para entender como pode utilizar o paradigma no processo construtivo. Assim, o autor propõe disciplinas específicas de BIM em que a complexidade do trabalho desenvolvido pelos estudantes aumente gradativamente conforme eles avancem nas disciplinas. Então, posteriormente, o conhecimento poderia ser aplicado às demais disciplinas existentes no currículo do programa de graduação.

Ruschel, Andrade e Morais (2013) classificaram a utilização do BIM segundo os estágios de implementação e os níveis de competência. O resultado dessa seleção está apresentado no Quadro 1. Nesse caso, os níveis introdutório, intermediário e avançado estabelecem qual o estágio de adoção de BIM seria correspondente. No primeiro nível, a ênfase se encontra na modelagem paramétrica, voltada a uma fase do processo do empreendimento (projeto, construção ou operação). O segundo estágio objetiva o compartilhamento multidisciplinar do modelo e requer uma coordenação dos projetos, ou seja, os alunos trabalham com um mesmo modelo em até duas disciplinas. Na terceira etapa, a ênfase está no desenvolvimento compartilhado e colaborativo do modelo da edificação, envolvendo todas as fases do ciclo consideradas pelos autores e diferentes disciplinas da área de AEC, assim essas múltiplas disciplinas compartilhariam um mesmo modelo de forma integrada e compartilhada (RUSCHEL; ANDRADE; MORAIS, 2013). 
Quadro 1 - Parâmetros de classificação das experiências didáticas de ensino de BIM

\begin{tabular}{|c|c|c|c|c|c|}
\hline \multirow[b]{2}{*}{$\begin{array}{c}\text { Nível de } \\
\text { competência }\end{array}$} & \multirow[b]{2}{*}{$\begin{array}{c}\text { Habilidade } \\
\text { desenvolvida }\end{array}$} & \multirow{2}{*}{$\begin{array}{c}\text { Representação } \\
\text { do estágio de } \\
\text { adoção do } \\
\text { BIM }\end{array}$} & \multicolumn{3}{|c|}{ Parâmetros de classificação } \\
\hline & & & $\begin{array}{l}\text { Modelo de } \\
\text { Informação }\end{array}$ & $\begin{array}{l}\text { Fases do } \\
\text { ciclo }\end{array}$ & $\begin{array}{l}\text { Resultados } \\
\text { obtidos }\end{array}$ \\
\hline Introdutório & $\begin{array}{l}\text { Habilita } \\
\text { como } \\
\text { modelador }\end{array}$ & Primeiro & $\begin{array}{l}\text { Modelagem e } \\
\text { produtividade }\end{array}$ & $\begin{array}{l}\text { Projeto ou } \\
\text { construção } \\
\text { ou } \\
\text { operação }\end{array}$ & $\begin{array}{l}\text { - } \quad \text { Modelagem } \\
\text { paramétrica; } \\
\text { - } \quad \text { Quantitativos; } \\
\text { - } \quad \text { Documentação. }\end{array}$ \\
\hline Intermediário & $\begin{array}{l}\text { Habilita } \\
\text { como } \\
\text { analista }\end{array}$ & Segundo & $\begin{array}{l}\text { Integração de } \\
\text { modelos e } \\
\text { uso aplicado } \\
\text { dos modelos } \\
\text { de } \\
\text { informação }\end{array}$ & $\begin{array}{l}\text { Projeto e } \\
\text { construção, } \\
\text { projeto e } \\
\text { operação } \\
\text { ou } \\
\text { operação e } \\
\text { construção }\end{array}$ & $\begin{array}{l}\text { - Simulações } \\
\text { (dimensionamento, } \\
\text { ambientais, 4D, } \\
\text { 5D, etc.), } \\
\text { compatibilização; } \\
\text { - Planejamento } \\
\text { (caminhos críticos, } \\
\text { linha de balanço). }\end{array}$ \\
\hline Avançado & $\begin{array}{c}\text { Habilita } \\
\text { como gerente }\end{array}$ & Terceiro & $\begin{array}{l}\text { Elaboração } \\
\text { compartilhada } \\
\text { e holística do } \\
\text { modelo de } \\
\text { informação }\end{array}$ & $\begin{array}{l}\text { Projeto, } \\
\text { construção } \\
\text { e operação }\end{array}$ & $\begin{array}{l}\text { - Introdução ao } \\
\text { Desenvolvimento } \\
\text { de Projetos } \\
\text { Integrados (IPD - } \\
\text { Integrated Project } \\
\text { Delivery); } \\
\text { - Colaboração } \\
\text { envolvendo } \\
\text { múltiplos agentes; } \\
\text { - Criação } \\
\text { compartilhada. }\end{array}$ \\
\hline
\end{tabular}

Fonte: modificado de Ruschel, Andrade e Morais (2013).

A estratégia de ensino-aprendizagem apresentada por Barison e Santos (2010) baseia-se na colaboração para a elaboração dos trabalhos desenvolvidos nas disciplinas, podendo ser: intracursos, aplicada em única disciplina, com alunos do mesmo curso desempenhando diferentes papéis no desenvolvimento do modelo colaborativo; interdisciplinar, em que ocorre a colaboração de alunos de diferentes disciplinas, para desenvolvimento e análise do modelo, de uma mesma universidade; ou a distância, em que alunos de diferentes universidades com cursos de AEC simulam o desenvolvimento de modelo BIM em conjunto, através de uma comunicação virtual.

Em outra estratégia proposta pelos autores Barison e Santos (2011) também é seguida uma divisão por níveis, na qual para cada nível de competência será adquirido um nível de proficiência dependente do conteúdo e tempo de estudo. Assim, tem-se o modelador BIM, que produz modelos simples de edifícios e residências, e consegue extrair quantidades, manipular o modelo e aprender os tipos de componentes básicos, adquirindo uma fundamentação em conceitos BIM; o analista BIM, que deve conhecer os conceitos de BIM, os fundamentos de projeto e materiais de construção para utilizar outras ferramentas BIM, as técnicas avançadas de modelagem e os sistemas do edifício, bem como explorar as funcionalidades de família na ferramenta BIM; e o gerente BIM, que já deve possuir conhecimento sobre métodos de construção, variadas ferramentas e aplicativos BIM, e tecnologia de construção para aprender técnicas de BIM e processos relacionados.

Checcucci (2014) acredita que disciplinas integradas é a maneira mais adequada de abordar BIM na graduação, pois permite uma formação mais abrangente e em um processo contínuo durante todo o curso. Para isso o método de ensino-aprendizagem Project/Problem Based Learning (PLB), Aprendizagem Baseada em Projeto/Problema, seria um meio adequado, já que as habilidades dos discentes são desenvolvidas através da resolução de problemas, que promovem maior participação dos envolvidos.

\section{Metodologia}

A metodologia adotada para consecução desta pesquisa contemplou as seguintes etapas:

(a) etapa I - revisão bibliográfica: reunião de conhecimentos disponíveis em livros, artigos 
publicados em revistas, artigos publicados em congressos, normas técnicas, dissertações de mestrado e teses de doutorado, que estivessem relacionados ao gerenciamento de projeto, à Modelagem da Informação da Construção e às estratégias de ensino de BIM nacional e internacionalmente. Esta etapa permitiu construir um referencial teórico e estabelecer os parâmetros que deveriam ser levados em consideração na análise dos resultados do estudo de caso;

(b) etapa II - descrição do caso estudado: detalhamento de como foi conduzida a disciplina de Gerenciamento de Projeto da Construção I, do inglês Construction Project Management I (CPM I), frequentada por um dos autores deste trabalho durante o segundo semestre de 2014 e que foi utilizada para exemplificar como o BIM é ministrado em uma universidade americana. Os aspectos descritos se referem aos objetivos da disciplina, ao material bibliográfico e aos programas utilizados como referência de estudo, aos conteúdos apresentados durante as aulas e ao trabalho final desenvolvido em grupo; e

(c) etapa III - análise dos resultados: o método de implantação do paradigma BIM dentro da disciplina de CPM I foi analisado e pôde ser classificado de acordo com as estratégias de ensino-aprendizagem de BIM apresentadas no referencial teórico.

\section{Estudo de caso}

Arizona State University (ASU) é uma universidade norte-americana, localizada no Estado do Arizona, que possui cinco campi espalhados pela região metropolitana de Phoenix. A Escola de Engenharia, Ira. Fulton School of Engineering, encontra-se localizada no campus de Tempe, e é responsável pelos programas de engenharia, gestão e tecnologia da informação.

Dentre esses programas está a Del E. Webb School of Construction Programs (Programas da Escola de Construção), que disponibiliza o curso de Gerenciamento da Construção (Construction Management), visando formar profissionais que combinem os conhecimentos de tecnologias inovadoras, princípios da construção e gestão de negócios, que conduzam uma grande variedade de projetos de construção, como edificações residenciais e comerciais, estradas e pontes (ARIZONA..., 2014).

Nesse curso, a graduação é realizada num período de quatro anos, sendo $60 \%$ do currículo dedicado às matérias relacionadas à engenharia e $40 \%$ focado em negócios. É importante ressaltar que no
Brasil grande parte dos conteúdos ensinados nas disciplinas do curso de graduação de Gerenciamento da Construção estão inseridos dentro do curso de graduação em Engenharia Civil, podendo ser analisado como tal.

\section{Descrição da disciplina de Gerenciamento de Projeto da Construção I da ASU}

A disciplina de Gerenciamento de Projeto da Construção I (Construction Project Management I - CPM I) é lecionada durante o quarto ano do curso. Portanto, é destinada aos semestres finais na graduação. Tem como pré-requisito a disciplina de Segurança na Construção (Construction Safety) e como correquisito a disciplina de Planejamento e Programação da Construção (Construction Planning and Scheduling), ambas cursadas pela autora. A primeira é equivalente à disciplina de Engenharia de Segurança do Trabalho, cursada na Escola Politécnica de Pernambuco, e à disciplina de Planejamento e Programação da Construção, cursada anteriormente na ASU.

O componente curricular CPM I foi cursado no ano de 2014, logo a metodologia da implantação do BIM no curso de Engenharia Civil em uma universidade americana pôde ser acompanhada por completo, provendo as informações para o estudo de caso.

As principais características da disciplina foram destacadas no Quadro 2.

Como primeira característica avaliada, infere-se que o paradigma BIM é inserido no conteúdo principal da disciplina, que são os conceitos referentes ao gerenciamento de projetos. Durante o semestre foram realizados 43 encontros que abrangeram as aulas teóricas (representando 35\% da carga horária), as aulas práticas (35\%), as palestras de profissionais da indústria $(23 \%)$ e a realização de três exercícios escolares (7\%).

Gerenciamento do Projeto da Construção I era a única disciplina lecionada pelo professor doutor Steven K. Ayer na ASU, sendo o segundo semestre do ano de 2014 a sua primeira turma na universidade. A disciplina foi conduzida nos semestres anteriores pelo professor doutor Allan D. Chasey.

O professor Ayer foi assessorado por dois monitores que se encontravam em processo de candidatura ao $\mathrm{PhD}$ em Gerenciamento de Projeto pela ASU durante aquele semestre e que auxiliaram os alunos tanto nas aulas teóricas quanto nas práticas. 


\section{Quadro 2 - Características relevantes da disciplina de CPM I}

\begin{tabular}{|c|c|}
\hline Duração & 6 meses. \\
\hline Tipos de aula & Teóricas e práticas. \\
\hline Número de aulas semanais & 2 aulas teóricas ( 75 minutos cada uma) e 1 aula prática (120 minutos). \\
\hline Período indicado & $7^{\circ}$ período (penúltimo semestre). \\
\hline Número de alunos & 45 alunos. \\
\hline $\begin{array}{l}\text { Principais assuntos } \\
\text { contemplados }\end{array}$ & $\begin{array}{l}\text { Gestão do projeto, modelagem e informação da construção e } \\
\text { metodologia de construção sustentável, através da filosofia da } \\
\text { Construção Enxuta (Lean Construction) e do sistema de acreditação } \\
\text { Leadership in Energy and Environmental Design (LEED). }\end{array}$ \\
\hline Objetivos & $\begin{array}{l}\text { - Explanação do processo de gerenciamento de projeto; } \\
\text { - } \quad \text { Descrição de filosofias e técnicas de controle de qualidade; } \\
\text { - } \quad \text { Identificação dos princípios básicos da construção sustentável; } \\
\text { - } \quad \text { Produção de um plano de implementação de BIM para um } \\
\text { empreendimento; } \\
\text { - Demonstração de como o BIM pode ser utilizado como suporte } \\
\text { - } \quad \text { Compara o processo construtivo; } \\
\text { - Descrição do planejamento de um sistema Lean Construction. }\end{array}$ \\
\hline
\end{tabular}

Fonte: adaptado de Ayer (2014).

O sistema de avaliação aplicado pelo professor considerava alguns parâmetros aos quais foi atribuído um peso correspondente para a nota final do aluno. A distribuição dos pesos foi realizada da seguinte maneira: a participação do estudante correspondia a $10 \%$ da nota; os três exercícios escolares representavam 40\%; aos exercícios propostos, derivados das palestras apresentadas nas aulas expositivas e das aulas práticas auxiliadas por computador, eram conferidos $10 \%$; e para cada parte do trabalho final (2 partes) foram designados $20 \%$ da nota. Portanto, além do método tradicional de avaliação que seria a prova escrita, o desempenho do aluno era continuamente avaliado pelo professor durante cada aula.

\section{Aulas teóricas}

Nas aulas expositivas foram apresentados os conceitos de gerenciamento de projeto com a utilização da metodologia de Modelagem da Informação da Construção e, em conjunto, nas palestras foram dados exemplos da utilização de diferentes usos do BIM pelos profissionais da indústria de AEC. Em geral, esses profissionais descreviam a área de atuação da empresa em que trabalhavam e discorriam sobre situações nas quais a utilização do paradigma proporcionou soluções mais efetivas do que quando empregado o método tradicional.

Para fornecer um suporte aos conteúdos abordados em sala de aula, foram disponibilizados materiais de referência e textos para leituras complementares por meio do sistema Blackboard, que funciona como uma sala de aula digital para cada disciplina, em que os alunos realizam o acesso através do login no sistema geral da universidade (My ASU), e possibilita que todo conteúdo e mensagens disponibilizados pelos professores sejam acessados por todos os alunos matriculados na disciplina.

Os textos complementares eram disponibilizados previamente a aula que o assunto abordado se referia. Desse modo, os alunos teriam uma noção do conteúdo que seria ministrado a seguir. Já o material de referência eram guias e normas que auxiliaram no entendimento do BIM e na sua implementação.

\section{Aulas práticas}

As aulas práticas eram desenvolvidas no laboratório de informática, ministradas em dois dias da semana, e cada dia era destinado a uma metade da turma. Essas aulas tinham como objetivo capacitar os estudantes nas plataformas utilizadas e demonstrar como poderiam ser empregadas para o desenvolvimento de um uso do BIM, com a utilização dos softwares apresentados no Quadro 3.

Para cada aula eram desenvolvidos trabalhos práticos que tinham como objetivo aumentar a afinidade dos estudantes com a plataforma utilizada e demonstrar como poderia ser empregada para o desenvolvimento de um uso do BIM, com o prazo de uma semana para conclusão.

É válido ressaltar que cada aluno tinha acesso a um computador do laboratório durante as aulas, e no horário extraclasse as dependências e os equipamentos do laboratório eram de livre acesso aos alunos. 
Quadro 3 - Descrição dos programas utilizados na disciplina e seus usos

\begin{tabular}{|c|l|}
\hline Software & \multicolumn{1}{c|}{ Utilização na disciplina } \\
\hline Autodesk Revit & $\begin{array}{l}\text { Software de planejamento e construção, utilizado na criação de modelos e } \\
\text { objetos paramétricos de edificações e na quantificação de materiais (quantity } \\
\text { takeoff). }\end{array}$ \\
\hline $\begin{array}{c}\text { Autodesk Naviworks } \\
\text { Manage }\end{array}$ & $\begin{array}{l}\text { Software de revisão de projetos para profissionais de AEC, que possibilita } \\
\text { uma visão holística integrada dos modelos e dados para maior controle sobre } \\
\text { o projeto e que permitiu a navegação no modelo digital, a modelagem 4D } \\
\text { (construção através do tempo) e a identificação de conflitos entre os sistemas } \\
\text { da edificação. }\end{array}$ \\
\hline Google Earth & $\begin{array}{l}\text { Globo virtual, com informações geográficas através da sobreposição de } \\
\text { imagens. Algumas de suas imagens foram utilizadas no modelo desenvolvido } \\
\text { no SketchUp. }\end{array}$ \\
\hline Google SketchUp & $\begin{array}{l}\text { Software de modelagem de rascunhos tridimensionais de fácil utilização, que } \\
\text { permite a criação de modelo e objetos e o desenvolvimento de logísticas do } \\
\text { canteiro de obras. }\end{array}$ \\
\hline Bluebeam Revu & $\begin{array}{l}\text { Permite criar, editar e fazer anotações em um arquivo no formato PDF. Na } \\
\text { disciplina permitiu a criação de hyperlinks nos documentos do projeto, } \\
\text { tabelas com quantitativos e orçamentos de materiais, e a transcrição de } \\
\text { modelo interativo do formato RVT para PDF, para utilização em tablets. }\end{array}$ \\
\hline Microsoft & $\begin{array}{l}\text { Software destinado ao gerenciamento de projetos, utilizado para formulação } \\
\text { do cronograma de projeto com gráfico de Gantt que pôde ser importado pela } \\
\text { plataforma Naviworks para o BIM 4D. }\end{array}$ \\
\hline
\end{tabular}

Os temas propostos nas aulas práticas foram: modelagem, logística do canteiro de obras, navegação no modelo, detecção de conflitos entre sistemas, instalações e componentes do projeto, gestão de atividades e funcionalidades, e cronograma de obras (modelo 4D).

\section{Trabalho final}

Uma parte importante da disciplina foi desenvolvida no trabalho final, no qual os alunos foram orientados a formar grupos compostos de quatro alunos e apenas um grupo com cinco alunos, que representariam uma empresa fictícia responsável por preparar o planejamento da construção de uma clínica médica localizada em Phoenix, Arizona. Esse empreendimento possuía como proprietário fictício o professor da disciplina, que transmitiu todas as informações necessárias para que o projeto dessa edificação fosse desenvolvido utilizando algumas das funcionalidades do BIM, de modo a atender aos seus objetivos.

Foram estabelecidos os usos do BIM que as equipes deveriam desempenhar e também foi requerida a sugestão de outros usos. Portanto, o grupo deveria demonstrar ao dono do empreendimento como a utilização dessa modelagem no empreendimento agregaria valor ao produto.
Além dessas informações, o professor/proprietário disponibilizou os modelos do empreendimento (arquitetura, estrutura e instalações elétricas, hidráulicas e mecânicas), o tempo previsto para conclusão da obra (24 meses) e os modelos dos documentos para a entrega dos relatórios escritos do Plano de Execução do Projeto BIM (Building Information Modeling Project Execution Planning (PxP)) e da Proposta de Projeto BIM (BIM Project Proposal). Nesse caso, o Projeto BIM é um empreendimento desenvolvido com a utilização do processo de Modelagem da Informação da Construção.

Como primeira atividade foi requisitada a realização de um relatório inicial com os dados referentes ao nome da empresa, a divisão de tarefas entre os membros da equipe em cada uma das etapas do trabalho, a definição dos métodos de comunicação entre os membros (reuniões presenciais semanais e conferências via Skype), a identificação de como seria dado o compartilhamento das informações (pendrive, pastas compartilhadas na nuvem, e-mails, ou servidor) e um plano para a resolução de possíveis conflitos que viessem a acontecer. Essa seção visou simular alguns dos dados presentes nos contratos entre as firmas participantes do projeto BIM, garantindo um processo de criação integrado entre as diferentes partes. 
Plano de Execução do Projeto BIM (PxP)

Os grupos foram orientados a seguirem o procedimento do guia PxP da CICRG para criarem o Plano de Execução do Projeto BIM da clínica de saúde. Para isso inicialmente foram definidos os objetivos e as prioridades dos usos do BIM aplicados ao empreendimento, organizados no Quadro 4.

A seguir, foram desenvolvidos mapas para a visualização das etapas para utilização dos usos do BIM de forma particular (mapa individual detalhado por uso) e geral (mapa do processo geral). Nesses mapas foram estabelecidos a sequência de introdução dos usos de BIM no projeto, os documentos de referência necessários e os documentos gerados pelo processo.
O Plano de Execução do Projeto BIM contava ainda com uma planilha de troca de informações, que visava estabelecer em que fase do projeto cada uso seria desenvolvido, a equipe responsável, o momento em que as informações deveriam ser compartilhadas com os demais profissionais e o formato do arquivo gerado. Portanto, essa etapa serviu como um guia de organização de deveres e responsabilidades dos integrantes do grupo de alunos, e de como se daria o detalhamento dos elementos do modelo.

Além dos itens anteriores, foram estabelecidas no $\mathrm{PxP}$ as estratégias para o controle de qualidade do modelo, garantindo a confiabilidade dos dados gerados e a definição da estrutura tecnológica necessária, ou seja, a indicação dos softwares e hardwares necessários para a execução dos usos de BIM.

Quadro 4 - Objetivos principais do BIM para o projeto e suas relevâncias

\begin{tabular}{|c|c|c|c|}
\hline $\begin{array}{c}\text { Prioridade } \\
\text { (Alta/Média/Baixa) }\end{array}$ & Descrição do objetivo & Usos potenciais do BIM & Forma de escolha \\
\hline Média & $\begin{array}{l}\text { Aumentar a produtividade } \\
\text { em campo }\end{array}$ & $\begin{array}{c}\text { Revisão/construtibilidade } \\
\text { de projeto e coordenação } \\
\text { 3D }\end{array}$ & $\begin{array}{l}\text { Requerido pelo } \\
\text { proprietário }\end{array}$ \\
\hline Baixa & $\begin{array}{c}\text { Aumentar o nível de } \\
\text { sustentabilidade da } \\
\text { edificação }\end{array}$ & Análise energética & Sugerido pelo grupo \\
\hline Alta & $\begin{array}{l}\text { Identificar os conflitos } \\
\text { entre sistemas antes da } \\
\text { execução }\end{array}$ & Coordenação 3D & $\begin{array}{l}\text { Requerido pelo } \\
\text { proprietário }\end{array}$ \\
\hline Média & $\begin{array}{l}\text { Rastrear o progresso de } \\
\text { construção }\end{array}$ & $\begin{array}{c}\text { Modelo 4D } \\
\text { (planejamento de fases) }\end{array}$ & $\begin{array}{l}\text { Requerido pelo } \\
\text { proprietário }\end{array}$ \\
\hline Alta & $\begin{array}{c}\text { Aumentar e efetividade da } \\
\text { utilização do local }\end{array}$ & $\begin{array}{c}\text { Rastreamento e gestão da } \\
\text { área } \\
\end{array}$ & $\begin{array}{c}\text { Requerido pelo } \\
\text { proprietário }\end{array}$ \\
\hline Alta & $\begin{array}{l}\text { Identificar os itens aos } \\
\text { quais futuras modificações } \\
\text { no projeto trariam } \\
\text { mudanças significativas ao } \\
\text { custo final do } \\
\text { empreendimento }\end{array}$ & $\begin{array}{c}\text { Estimativa de custo de } \\
\text { itens representativos para } \\
\text { o projeto }\end{array}$ & $\begin{array}{l}\text { Requerido pelo } \\
\text { proprietário }\end{array}$ \\
\hline Alta & $\begin{array}{c}\text { Incorporar dados para } \\
\text { futuros empreendimentos } \\
\text { do proprietário }\end{array}$ & $\begin{array}{l}\text { Revisão do modelo e } \\
\text { fabricação digital }\end{array}$ & $\begin{array}{c}\text { Requerido pelo } \\
\text { proprietário/Sugerido } \\
\text { pelo grupo } \\
\end{array}$ \\
\hline Média & $\begin{array}{c}\text { Efetuar rápida avaliação } \\
\text { do desempenho do projeto }\end{array}$ & $\begin{array}{c}\text { Análise de sistema da } \\
\text { edificação }\end{array}$ & Sugerido pelo grupo \\
\hline Alta & $\begin{array}{l}\text { Registrar modelo preciso } \\
\text { em 3D para a equipe de } \\
\text { gestão da edificação }\end{array}$ & $\begin{array}{l}\text { Registro de modelagem e } \\
\text { coordenação 3D }\end{array}$ & $\begin{array}{l}\text { Requerido pelo } \\
\text { proprietário }\end{array}$ \\
\hline Baixa & $\begin{array}{l}\text { Aumentar a efetividade } \\
\text { energética da instalação }\end{array}$ & $\begin{array}{l}\text { Análise energética e } \\
\text { análise de iluminação }\end{array}$ & Sugerido pelo grupo \\
\hline Média & $\begin{array}{c}\text { Diminuir os custos totais } \\
\text { em manutenção }\end{array}$ & Registro de modelo & $\begin{array}{c}\text { Requerido pelo } \\
\text { proprietário }\end{array}$ \\
\hline
\end{tabular}

Fonte: Feitosa et al. (2014a). 
O desenvolvimento do Plano de Execução proporcionou aos alunos a compreensão da importância de um estudo prévio do projeto, ou seja, considerar todas as possíveis alternativas que se adequariam ao objetivo do projeto e selecionar as mais relevantes, além de organizar de forma geral como o projeto seria desenvolvido pelas partes envolvidas.

Além disso, o plano permitiu a preparação das equipes a fim de garantir que as ações sejam finalizadas dentro do prazo estabelecido, com o nível de especificação determinado e com a qualidade necessária.

\section{Proposta de Projeto BIM}

$\mathrm{Na}$ segunda parte do trabalho final os alunos deveriam desenvolver a Proposta de Projeto BIM, em que demonstrariam suas intenções acerca de como construiriam a clínica médica, e a abordagem do BIM em cada fase do gerenciamento de projeto (início, organização e preparação, execução do trabalho, monitoramento e controle, e encerramento).

De início foram definidas as estratégias de trabalho, nas quais os alunos deveriam explicar e aplicar os conceitos de Construção Enxuta (Lean Construction) e de Liderança no Projeto de Energia e Ambiente (Leadership in Energy and Environmental Design (LEED)), de forma a promover o desenvolvimento de projetos sustentáveis pelos estudantes.

Como conteúdo principal dessa proposta tem-se as descrições de como seria realizado o desenvolvimento de cada uso do BIM apresentado anteriormente, e os exemplos dos resultados adquiridos com a sua utilização. Esses usos foram divididos entre as etapas de planejamento, execução, controle do projeto (qualidade do projeto, atrasos e excedentes de custo) e encerramento, de forma a seguir o ciclo de vida do projeto. Dentre os resultados produzidos pelos usos do BIM estão:

(a) revisão/construtibilidade do projeto: foi utilizado como meio de avaliar se os requisitos do proprietário haviam sido atendidos, permitindo que fossem efetuadas mudanças no projeto ou nos materiais utilizados sem grande impacto no custo. Para o desenvolvimento do modelo, demonstrado na Figura 5, foi utilizado o Revit, e para a realização de uma visita virtual à edificação foi utilizado o Navisworks Manage;

(b) estimativa de custos: a partir do modelo fornecido pelo professor, foi possível realizar o quantitativo automático de materiais e, então, prover o custo estimado para a construção da área estudada. Esse processo foi realizado com o auxílio do modelo do Revit e das funcionalidades do software Bluebeam Revu;

(c) planejamento da utilização do canteiro de obras: para obtenção desse resultado foi utilizado o software SketchUp. Uma imagem da localização da obra foi importada do Google Earth e, a partir desta, foi realizada a modelagem do canteiro de obras pelo grupo em três diferentes fases da execução da obra (fase inicial, fase intermediária e fase final). Uma vista do modelo do canteiro de obras referente à fase intermediária da construção está apresentada na Figura 6. Esse uso de BIM permitiu a identificação de áreas potenciais e críticas no canteiro, a visualização das entradas de acesso, a logística do canteiro e o impacto da edificação nas áreas próximas;

(d) coordenação 3D: desenvolvida na plataforma Navisworks, além de permitir a avaliação prévia das instalações pelo dono do empreendimento, possibilitou que fossem realizadas detecções de conflitos entre os diferentes sistemas da edificação integrados no modelo 3D. Um exemplo de conflito encontrado no projeto foi a presença de um tubo das instalações hidráulicas (em preto) passando no interior de uma viga metálica da estrutura da edificação (em branco) presentes na Figura 7;

(e) controle: os usos da Modelagem de Informação da Construção empregados para o controle da edificação foram a fabricação digital e as análises de iluminação e energética desenvolvidas na plataforma Revit. A fabricação digital é justificada pela importância da qualidade do modelo de fabricação e de um agendamento de entrega coordenado com o andamento da construção, evitando possíveis atrasos. Já a análise de iluminação foi sugerida pelo grupo devido à influência que a iluminação pode ter em diagnósticos médicos. Por fim, a análise energética proporciona ao proprietário/professor uma visão de quanto seria consumido em termos de energia elétrica e combustível durante a utilização das instalações da edificação, o que permite adequações prévias para alcançar uma melhor eficiência energética; e

(f) registro de modelagem: foi indicado como forma de garantir que durante todas as fases da construção o modelo fosse constantemente atualizado com as possíveis modificações realizadas no momento da execução. 
Figura 5 - Perspectiva externa do modelo renderizado da clínica de saúde

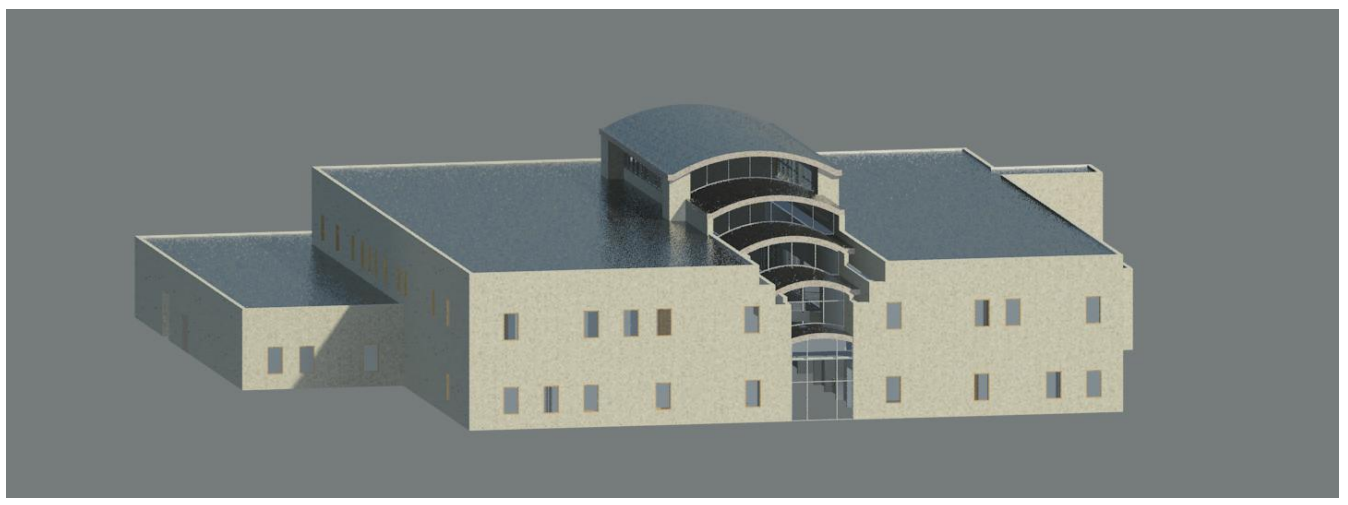

Fonte: Feitosa et al. (2014b).

Figura 6 - Plano da utilização do canteiro de obras na fase intermediária da construção

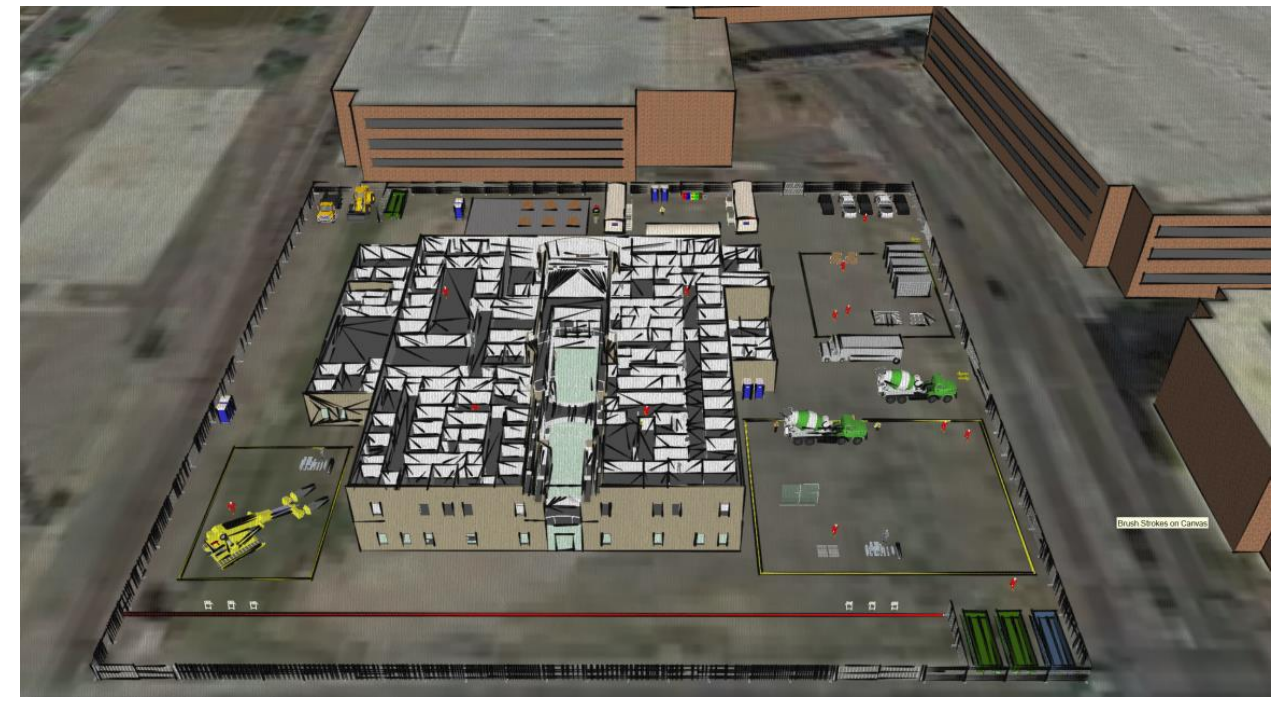

Fonte: Feitosa et al. (2014b).

Figura 7 - Interferência identificada entre a estrutura metálica e as instalações hidráulicas

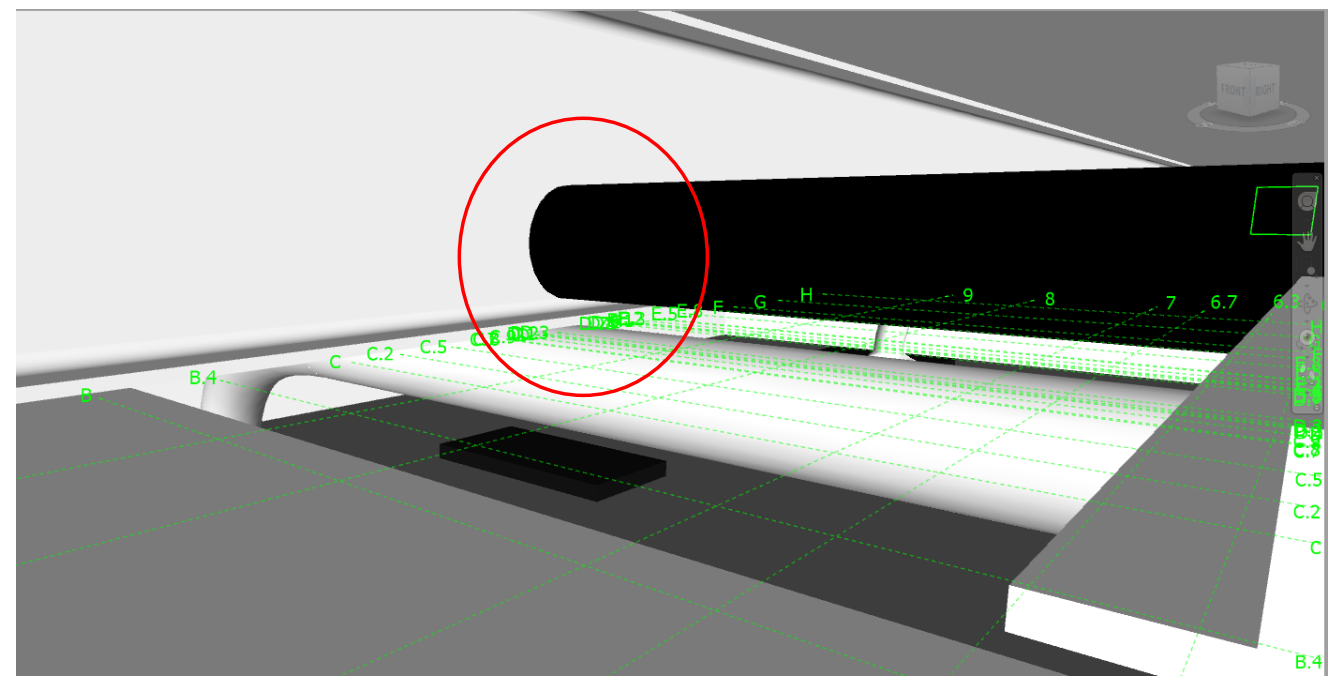

Fonte: Feitosa et al. (2014b). 
Após a entrega desta proposta de projeto foi realizada uma breve apresentação ao proprietário/professor e seus consultores (um professor convidado, responsável pela disciplina de Gerenciamento de Projeto de Engenharia Civil, $\mathrm{e}$ os dois monitores da disciplina). Esta apresentação deveria conter uma visão geral do projeto, demonstrar os principais interesses do proprietário identificados pela equipe, apresentar os componentes-chave do plano da equipe para o beneficiamento do projeto e reiterar como a empresa atendia aos interesses do proprietário e por que deveria ser escolhida para realização da obra.

Assim, os discentes tiveram a oportunidade de apresentar suas abordagens ao dono do empreendimento e justificar como os métodos por eles escolhidos se adequariam aos objetivos iniciais e agregariam valor ao projeto.

\section{Análise dos resultados}

Através deste estudo percebe-se que a disciplina de Gerenciamento de Projetos da Construção abordou a Modelagem da Informação da Construção como paradigma a ser utilizado para obtenção de melhores resultados no gerenciamento de projetos, tendo esse assunto foco maior dentro de suas aulas práticas.

A inserção dos profissionais da indústria de AEC compartilhando suas experiências relacionadas ao gerenciamento de projetos e ao BIM agregou uma visão prática dos assuntos abordados dentro da sala de aula. Além disso, suas diferentes áreas de atuação permitiram que os estudantes realizassem questionamentos sobre assuntos diversificados.

O trabalho final promoveu a utilização dos vários conhecimentos adquiridos na disciplina, demonstrando como eles estão presentes no processo de gerenciamento de projeto. A divisão do trabalho em duas partes, o Plano de Execução do Projeto BIM e a Proposta de Projeto BIM, permitiu que este fosse desenvolvido no decorrer do semestre.

Além disso, o trabalho funcionou como uma simulação do processo seletivo para escolha da empresa a ser contratada para execução do projeto de um cliente. Isso fez com que os alunos se deparassem com a necessidade de atender os interesses do dono do empreendimento e de demonstrar a qualidade do seu trabalho.

É importante ressaltar que neste trabalho foi promovido o compartilhamento de informações entre alunos da mesma disciplina e do mesmo curso. Logo, apesar de promover a colaboração durante $\mathrm{o}$ projeto, a ausência da multidisciplinaridade fez com que os estudantes não desenvolvessem plenamente uma visão de outras etapas do projeto e do processo de comunicação para o desenvolvimento do modelo.

Por ser a única disciplina do curso que aborda o tema, tem de fazê-lo de forma abrangente e cobrindo um conteúdo extenso, sem conferir maior aprofundamento. Assim, uma sugestão seria a abordagem dos conceitos de BIM em outras disciplinas do curso, o que possibilitaria a criação de projetos de maior complexidade e detalhamento desse tema. Também poderia ser incentivado o compartilhamento do modelo com alunos do curso de arquitetura.

\section{Conclusões}

A Modelagem da Informação da Construção (BIM) é um paradigma relativamente recente que engloba a expressão gráfica e o gerenciamento de projeto da construção em um mesmo ambiente virtual. O modelo de informação agrega uma grande variedade de descrições sobre os elementos da edificação e permite executar simulações para uma visualização de como o empreendimento irá se comportar em vários aspectos. Logo, o BIM proporciona uma série de benefícios para os seus usuários, que poderão adaptar o seu uso às necessidades momentâneas.

No entanto, ainda na atualidade a utilização do BIM ocorre de maneira pouco difundida, inclusive no Brasil. No referencial teórico foi observado que a falta de experiência e o desconhecimento sobre o tema podem ser considerados desafios para sua utilização. Assim, a implementação do ensino da Modelagem da Informação da Construção no ambiente acadêmico proveria a base necessária para a formação de profissionais que incentivassem a utilização do BIM e atendessem aos requisitos das empresas que utilizam essa metodologia.

Através das estratégias de ensino apresentadas para inserção da Modelagem da Informação nos cursos de graduação, foi identificado que o conteúdo poderia ser abordado na forma de disciplina específica do BIM ou como recurso utilizado em outra disciplina. Além disso, a introdução do paradigma no currículo da graduação pode ser feito em diferentes níveis de complexidade (introdutório, intermediário e avançado).

Acerca do estudo de caso da disciplina de Gerenciamento de Projeto da Construção I (CPM I), o método de abordagem do BIM na Arizona State University foi a inserção dos conceitos de BIM em conjunto com os demais assuntos de uma disciplina existente. 
A disciplina de CPM I pôde ser classificada, quanto ao nível de complexidade, como de nível intermediário, formando um analista BIM. Esse nível foi atribuído devido ao fato de serem contemplados os fundamentos e a modelagem do BIM. A disciplina abrange mais de uma fase do ciclo de vida da construção, e são desenvolvidos modelos 4D e 5D com cronograma da construção. Ademais, não são desenvolvidas habilidades avançadas de modelagem e também não foi incentivada a colaboração de alunos de diferentes disciplinas ou cursos.

Ainda assim a disciplina se mostrou efetiva em contemplar os principais conceitos e usos da Modelagem da Informação da Construção, demonstrar como pode ser utilizado durante a vida profissional e despertar o interesse dos alunos pelo tema, constituindo-se como um bom exemplo de como o BIM pode ser abordado durante a graduação em engenharia civil.

Em estudos futuros poderia ser realizado um estudo de caso similar abordando o método de ensino de BIM nas universidades brasileiras, que além de apresentar um exemplo no contexto nacional, permitiria estabelecer algumas comparações entre as abordagens brasileira e americana.

\section{Referências}

ARIZONA STATE UNIVERSITY. Construction Management: Del E. Webb School of Construction. Tempe: ASU, 2014. Disponível em: $<$ http://ssebe.engineering.asu.edu/prospectivestudents/construction-management.html >. Acesso em: 14 nov. 2015.

\section{ASSOCIATED GENERAL CONSTRACTORS OF AMERICA. AGC Contractor's Guide to BIM. AGC, 2006. Disponível em: $<$ http://www.tpm.com/wp- content/uploads/2013/02/AGC_Guide_to_BIM.pdf >. Acesso em: 2 nov. 2015.}

AYER, S. Course Project: BIM project execution plan and project BIM proposal. Diretrizes para execução do projeto final da disciplina de Construction Project Management I. Tempe: ASU, 2014.

AZHAR, S. Building Information Modeling (BIM): trends, benefits, risks, and challenges for the AEC Industry. Leadership and Management in Engineering, v. 11, n. 3, p. 241-252, 2011.

BARISON, M.; SANTOS, E. Estratégias de Ensino BIM: uma visão geral das abordagens atuais. In: INTERNATIONAL CONFERENCE ON COMPUTING IN CIVIL AND BUILDING
ENGINEERING, 12., Nottingham, 2010. Proceedings... Nottingham: ICCCBE, 2010.

BARISON, M.; SANTOS, E. Ensino de BIM: tendências atuais no cenário internacional. Gestão \& Tecnologia de Projetos, São Carlos, v. 6, n. 2, p. 67-80, dez. 2011.

COMPUTER INTEGRATED CONSTRUCTION RESEARCH GROUP. Building Information Modeling Project Execution Planning Guide version - 2.1. University Park: Pennsylvania State University, 2011.

CHECCUCCI, E. Ensino-Aprendizagem de BIM nos Cursos de Graduação em Engenharia Civil e o Papel da Expressão Gráfica Neste Contexto. Salvador, 2014. 235 f. Tese (Doutorado Multiinstitucional e Multidisciplinar em Difusão do Conhecimento) - Faculdade de Educação da Universidade Federal da Bahia, Salvador, 2014.

CLEVENGER, C. M. et al. Integrating BIM Into Construction Management Education. In: THE BIM-RELATED ACADEMIC WORKSHOP, Washington, 2010. Proceedings... Washington, 2010 .

DINSMORE, P.; CABANIS-BREWIN, J. AMA Manual de Gerenciamento de Projetos. Rio de Janeiro: Brasport, 2009.

EASTMAN, C. et al. BIM Handbook: a guide to Building Information Modeling for owners, managers, designers, engineers, and contractors. 2 . ed. New Jersey: John Wiley \& Sons, 2011.

\section{FEITOSA, A. et al. Building Information}

Modeling (BIM) Project Execution Plan - Solve Design \& Construction. 2014. Trabalho referente à nota parcial da disciplina de Construction Project Management I. Tempe: ASU, 2014a. Disponível em: <http://bimexperts.com.br/wpcontent/uploads/2015/12/Solve_PxP.pdf $>$. Acesso em: 8 dez. 2015.

\section{FEITOSA, A. et al. Building Information}

Modeling Proposal - Solve Design \&

Construction. 2014. Trabalho apresentado como componente da nota parcial da disciplina de Construction Project Management I. Tempe: ASU, 2014b. Disponível em:

<http://bimexperts.com.br/wpcontent/uploads/2015/12/Solve_construction_BIM _proposal.pdf>. Acesso em: 8 dez. 2015.

GODOY, V.; CARDOSO, C.; BORGES, M. BIM: desafios para um conceito em construção no ensino de arquitetura e engenharia. In: CONGRESSO BRASILEIRO DE EDUCAÇÃO EM ENGENHARIA, 41., Gramado, 2013. Anais... Gramado: Cobenge, 2013. 
INFOCOMM INTERNATIONAL. Building Information Modeling (BIM) Guide. InfoComm International, 2011. Disponível em:

<http://www.infocomm.org/cps/rde/xbcr/infocom m/Brochure_BIM.pdf $>$. Acesso em: 18 out. 2015.

\section{KYMMELL, W. Building Information}

Modeling: planning and managing construction projects with 4D CAD and simulations. New York: McGraw Hill, 2008.

LINO, J. C.; AZENHA, M.; LOURENÇO, P. Integração da Metodologia BIM na Engenharia de Estruturas. In: ENCONTRO NACIONAL BETÃO ESTRUTURAL, Porto, 2012. Anais... Porto: FEUP, 2012.

MELHADO, S. et al. A Gestão de Projetos de Edificações e o Escopo de Serviços Para Coordenação de Projetos. Téchne, São Paulo, v, 135, jun. 2008.

MELLO, R. BIM e Custos: maximize os dados do modelo com o Navisworks e o Quantity Takeoff. Autodesk University Brasil, 2012. Disponível em: <http://staticwd.autodesk.net/content/dam/au/Brasil2014/documents/materialapoio/2012/AUBR44_Apostila.pdf $>$. Acesso em: 1 nov. 2015.

MELO, R. Building Information Modeling (BIM) Como Ferramenta na Compatibilização de Projetos Para Construção Civil. Formiga, 2014. 94 f. Trabalho de Conclusão de Curso (Bacharelado em Engenharia Civil) - Centro Universitário de Formiga, Formiga, 2014.

NATIONAL INSTITUTE OF BUILDING SCIENCES. National BIM Standard - United States Version 3. NIBS building SMARTalliance: Washington, 2015. Disponível em: <https://www.nationalbimstandard.org/>. Acesso em: 29 maio 2016.

PEREIRA, P.; RIBEIRO, R. A Inserção do BIM no Curso de Graduação em Engenharia Civil. In: CONGRESSO BRASILEIRO DE EDUCAÇÃO EM ENGENHARIA, 42., Juiz de Fora, 2014. Anais... Juiz de Fora: Cobenge, 2014.
PROJECT MANAGER INSTITUTE. Guia

PMBOK: um guia do conhecimento em gerenciamento de projetos. 4. ed. Pennsylvania: Project Management Institute, 2008.

RUSCHEL, R.; ANDRADE, M.; MORAIS, M. O Ensino de BIM no Brasil: onde estamos?

Ambiente Construído. Porto Alegre, v. 13, n. 2, p. 151-165, abr./jun. 2013.

SABONGI, F. The Integration of BIM in the Undergraduate Curriculum: an analysis of undergraduate courses. In: ANNUAL CONFERENCE OF ASC, ASSOCIATED SCHOOL OF CONSTRUCTION, 45., Florida, 2009. Proceedings... Florida: Gainsville, 2009.

SACKS, R.; PIKAS, E. Building Information Modeling Education for Construction Engineering and Management: I, industry requirements state of the art, and gap analisys. Journal of Construction Engineering and Management, v. 139, n. 11, nov. 2013.

SANTOS, E. T.; BARISON, M. B. BIM e as Universidades. Construção Mercado, São Paulo, v. 115, fev. 2011.

SILVA, A.; CIM, M. Gestão de Projetos: disciplina na modalidade a distância. Florianópolis: SENAI/SC, 2012. Disponível em: $<$ http://docplayer.com.br/1006484-Gestao-deprojetos-disciplina-na-modalidade-adistancia.html>. Acesso em: 11 out. 2015.

SOUZA, L.; AMORIM, S.; LYRIO, A. Impactos do Uso do BIM em Escritórios de Arquitetura: oportunidades no mercado imobiliário. Gestão \& Tecnologia de Projetos, São Paulo, v. 4, n. 2, p. 26-53, nov. 2009.

\section{Agradecimentos}

Agradecimento à Capes, que por meio do programa de intercâmbio acadêmico Ciências sem Fronteiras proporcionou a experiência que desenvolveu o interesse pelo tema, e à Arizona State University pelo conhecimento adquirido e vivenciado que permitiu desenvolver o estudo de caso.

60 Basto, P. E. de A.; Lordsleem Junior, A. C. 
Priscilla Elisa de Azevedo Basto

Escola Politécnica | Universidade de Pernambuco | Rua Eduardo de Morais, 1130, Bairro Novo | Olinda - PE -Brasil | CEP $53130-120$ | Tel.: (81) 3439-4986 | E-mail: priscillabasto@gmail.com

Alberto Casado Lordsleem Júnior

Escola Politécnica | Universidade de Pernambuco | Rua Benfica, 455, Sala I-01, Madalena | Recife - PE - Brasil | CEP 50720-001 | Tel.: (81) 3184-7566 | E-mail: acasado@poli.br

Revista Ambiente Construído

Associação Nacional de Tecnologia do Ambiente Construído

Av. Osvaldo Aranha, $99-3^{\circ}$ andar, Centro

Porto Alegre - RS - Brasil

CEP $90035-190$

Telefone: +55 (51) 3308-4084

Fax: +55 (51) 3308-4054

www.seer.ufrgs.br/ambienteconstruido

E-mail: ambienteconstruido@ufrgs.br 